\title{
Imbalance of naive and memory T lymphocytes with sustained high cellular activation during the first year of life from uninfected children born to HIV-1-infected mothers on HAART
}

\author{
E. Ono ${ }^{1}$, A.M. Nunes dos Santos ${ }^{2}$, R.C. de Menezes Succi ${ }^{1}$, D.M. Machado ${ }^{1}$, \\ D.S.A. de Angelis ${ }^{4}$, R. Salomão ${ }^{3}$, E.G. Kallás ${ }^{3}$ and M.I. de Moraes-Pinto ${ }^{1}$
}

${ }^{1}$ Disciplina de Infectologia Pediátrica, ${ }^{2}$ Disciplina de Pediatria Neonatal, Departamento de Pediatria, ${ }^{3}$ Disciplina de Doenças Infecciosas, Departamento de Medicina, Escola Paulista de Medicina, Universidade Federal de São Paulo, São Paulo, SP, Brasil

${ }^{4}$ Laboratório de Virologia, Instituto de Medicina Tropical de São Paulo, Universidade de São Paulo, São Paulo, SP, Brasil

Correspondence to: M.I. de Moraes-Pinto, Disciplina de Infectologia Pediátrica, Departamento de Pediatria, EPM, UNIFESP, Rua Pedro de Toledo, 781, $9^{\circ}$ andar, 04039-032 São Paulo, SP, Brasil Fax: +55-11-5575-6928. E-mail: m.isabelmp@uol.com.br

The immune consequences of in utero HIV exposure to uninfected children whose mothers were submitted to highly active antiretroviral therapy (HAART) during gestation are not well defined. We evaluated 45 HIV-exposed uninfected (ENI) neonates and 45 healthy unexposed control (CT) neonates. All HIV-infected mothers received HAART during pregnancy, and the viral load at delivery was $<50$ copies $/ \mathrm{mL}$ for $56.8 \%$. Twenty-three ENI neonates were further evaluated after 12 months and compared to 23 unexposed healthy age-matched infants. Immunophenotyping was performed by flow cytometry in cord and peripheral blood. Cord blood lymphocyte numbers did not differ between groups. However, ENI neonates had a lower percentage of naive T cells than CT neonates (CD4+, 76.6 vs 83.1\%, $\mathrm{P}<0.001$; CD8+, 70.9 vs $79.6 \%, \mathrm{P}=0.003)$ and higher percentages of central memory T cells than CT neonates (CD4+, 13.9 vs 8.7\%, $\mathrm{P}<0.001$; CD8+, 8.6 vs $4.8 \%, \mathrm{P}=0.001)$. CD38 mean fluorescence intensity of T cells was higher in ENI neonates (CD4+, 62.2 vs 52.1, $\mathrm{P}=0.007$; CD8+, 47.7 vs 35.3, $\mathrm{P}<0.001)$. At 12 months, ENI infants still had higher mean fluorescence intensity of CD38 on T cells (CD4+, 34.2 vs 23.3, $P<0.001$; CD8+, 26.8 vs 19.4, $P=0.035$ ). Despite effective maternal virologic control at delivery, HIV-exposed uninfected children were born with lower levels of naive $T$ cells. Immune activation was present at birth and remained until at least 12 months of age, suggesting that in utero exposure to HIV causes subtle immune abnormalities.

Key words: Immunophenotyping; Highly active antiretroviral therapy; HIV-1; Immunological stimulation; Neonates of HIVinfected mothers

Research supported by FAPESP (\#01/11011-6) and CAPES.

Received February 25, 2008. Accepted August 4, 2008

\section{Introduction}

Worldwide, women account for nearly half of the 40 million people living with HIVIAIDS (1), leading to an estimated two million infants exposed every year to human immunodeficiency virus type 1 (HIV-1) during pregnancy and delivery (2).

The use of highly active antiretroviral therapy (HAART) in resource-rich countries has decreased the vertical transmission of HIV-1 to rates as low as $0.99 \%$ (3). However, 
being conceived and undergoing embryonic and fetal development in an environment modified by maternal HIV infection can have consequences that might go beyond HIV infection itself. A limited number of studies have addressed this issue $(4,5)$, highlighting the state of immune activation $(4,6)$ in children born to HIV-infected mothers. However, in these studies, data were collected from children whose mothers had not necessarily received HAART, the currently accepted antenatal treatment for maternal HIV infection (3).

In the present study, we evaluated several mononuclear cell parameters of HIV-1-exposed uninfected neonates (ENI) whose mothers were on triple therapy. Using flow cytometric analyses, we studied cord blood mononuclear cells, including $B$ cells, natural killer (NK) cells, CD34+ progenitors, CD4+ and CD8+ T subsets, along with their subpopulations and activation markers, and compared them to those in cord blood from neonates born to non-HIV-infected healthy control mothers (CT). The same analysis was performed on a subgroup of the HIV-exposed uninfected neonates at 12 months of age and the results were compared to those of healthy non-HIV-exposed infants of the same age.

Our aim was to determine whether non-HIV-infected children born to HIV-infected women on HAART would show evidence of immune activation and whether that state would be demonstrable at 12 months after birth.

\section{Subjects and Methods}

\section{Patients and study design}

The protocol was approved by the Ethics Committee of the Federal University of São Paulo. All mothers gave written informed consent prior to enrollment in the study. Ninety neonates born in two Maternity Units of the Federal University of São Paulo were evaluated from March 2004 to October 2005. HIV-1-exposed neonates (ENI neonates, $\mathrm{N}=45$ ) were given formula and not breast-fed. They were followed-up regularly at the Pediatric AIDS Outpatient Clinic of the Federal University of São Paulo, Brazil. The children were considered to be HIV-exposed uninfected if they had two negative HIV-RNA detection tests, with the second performed when the infant was 4 months old. Forty-five healthy term neonates born to HIV-negative mothers were included in the HIV-negative control neonate group (CT neonates).

The information collected included maternal age at delivery, maternal antiretroviral treatment, maternal viral load during pregnancy and at delivery, type of delivery, neonate birth weight, and gestational age.

Twenty-three of the 45 HIV-1-exposed neonates were also evaluated at 12 months of age (ENI infants) and were compared to another 23 healthy non-HIV-exposed infants of the same age (CT infants). Children from the control infant group were not part of the control neonate group. These infants were recruited at an outpatient clinic in São Paulo where they were part of a routine follow-up program of healthy infants. They were born at term weighing more than $2500 \mathrm{~g}$ without previous history of serious disease. At assessment, they did not present any diseases and were not on any medications.

\section{Neonate subset}

Forty-five exposed neonates (one pair of twins) born to 44 HIV-infected women and 45 neonates born to 45 HIVnegative women were analyzed. All mother-infant pairs were selected in 2 Maternity Units linked to the Federal University of São Paulo, and no socio-economical or racial differences were noted between groups. Mean age of the HIV-infected mothers was 4.4 years greater than the control group (HIV: 29.6 years vs CT: 25.2 years, $\mathrm{P}=0.001$, $t$-test). All 44 HIV-infected women received highly active antiretroviral prophylaxis during gestation, which consisted of two nucleoside reverse transcriptase inhibitors (NRTI) and one protease inhibitor in $29 / 44$ (65.9\%) of the women and of two NRTI and one non-nucleoside reverse transcriptase inhibitor (NNRTI) in 15/44 (34.1\%) of the women. Fifteen of the 44 HIV-infected women (34.1\%) received some antiretroviral treatment before pregnancy, which was modified in order to reduce viral load in some of them or to avoid toxic drugs, e.g., efavirenz. Twenty-eight of the $44(63.6 \%)$ women reached HIV viral load levels below 400 copies/mL and maintained those levels for 10.7 weeks (mean) during gestation. Viral load at delivery was below 50 copies/mL in 25 of 44 women (56.8\%). Mean viral load in the other 19 HIV-infected women was 1569.4 copies/ $\mathrm{mL}$. Elective caesarean section was performed in 37 of the 44 HIV-1-positive women and in 3 of the 45 HIV-seronegative women $(P<0.001$, chi-square test).

None of the mothers from the control group presented any infection during pregnancy that could be transmitted vertically. A total of 5 HIV-infected mothers of the 44 $(11.4 \%)$ had coinfections during pregnancy: 2 had serologic evidence of syphilis, 1 was hepatitis $\mathrm{C}(\mathrm{HCV})$ and human papillomavirus positive, 1 had genital herpes (HSV) and 1 had Pneumocystis jiroveci infection and toxoplasmosis. All mothers were treated during pregnancy for their coinfections. Also, neonates born to mothers with syphilis and toxoplasmosis were evaluated and treated after birth, without any signs or symptoms of congenital infections. Neither HCV nor HSV were transmitted to the children. One child born to an HIV-infected mother with an unevent- 
ful pregnancy but detected viral load at delivery (log 3.8 $\log / \mathrm{mL}$ ) had early sepsis due to Streptococcus viridans, which resolved after treatment. As for drug addition, 4 of the $44(10 \%)$ HIV-infected mothers reported use of cocaine or crack. None of the control mothers reported use of illicit drugs.

Mean birth weight and mean gestational age were lower in exposed neonates in comparison to the control ones (2874.8 vs $3358.1 \mathrm{~g}$ and 37.7 vs 39.6 weeks, respectively; $\mathrm{P}<0.001$ for both analyses, $t$-test). The characteristics of study subjects are summarized in Table 1.

\section{Infant subset}

Twenty-three exposed uninfected infants born to 22 HIV-infected women and 23 matched control infants were analyzed. Demographic and clinical characteristics were not different between the groups with respect to age (mean: 12.3 vs 12.4 months; $t$-test) and gender (65.2\% females among HIV-exposed vs $52.2 \%$ females among control infants; chi-square test).

\section{Blood collection and complete blood count}

Cord blood $(10 \mathrm{~mL})$ was collected from the umbilical vein. Twelve-month-old infants had a $5-\mathrm{mL}$ blood sample collected by peripheral vein access. The blood samples were put into EDTA-treated vacuum tubes for complete blood count, phenotypic analysis of peripheral blood mononuclear cell subsets using flow cytometric assays and plasma IL-7 levels. All samples were tested using Advia 120 automatic counter (Bayer, Ireland) and confirmed by a slide smear performed for manual count.
Flow cytometry analyses

Peripheral blood mononuclear cells were assessed by 4-color flow cytometry (FACSCalibur, BD Biosciences, USA) after cell staining using lyse-wash protocol and analyzed using the CellQuest software (BD Biosciences). Isotypic controls (IgG1-FITC, IgG1-PE, IgG1-APC, IgG2a$\mathrm{PE}$, all from BD Biosciences) were used to evaluate nonspecific staining. The number of cells per cubic milliliter of blood was obtained using the lymphocyte counts from the complete blood count.

\section{Cell subsets}

$C D 4+$ and $C D 8+T$ lymphocytes. The markers used to assess the subpopulation within the CD4+ (CD3-APC and CD4-PerCP labeled) and CD8+ (CD3+ and CD8-PerCP labeled) populations were CD45RA-FITC and CCR7-PE (BD Biosciences). In both CD4+ and CD8+ populations, the naive cells were CD45RA+CCR7+. The "central memory" cells were CD45RA-CCR7+ and the "effector memory" cells were CD45RA-CCR7-. The "terminally differentiated memory" cells, more abundantly seen among CD8+ cells than in the CD4+ cohort, were CD45RA+CCR7- $(7,8)$.

CD4+ and CD8+ T lymphocyte activation. Lymphocyte activation was evaluated by the expression of CD38 on CD4+ and on CD8+ T cells using two different approaches: the mean fluorescence intensity of single parameter histograms representing each population and the percentage of positive cells assessed with the use of isotype controls.

$B$ lymphocytes and NK cells. B lymphocytes were identified as CD3-CD19+ cells. NK cells were quantified by the CD45+CD3-CD56+CD16+ phenotype.

Table 1. Characteristics of study subjects.

\begin{tabular}{lll}
\hline Characteristic & ENI neonates & CT neonates \\
\hline Maternal age in years & $29.6(17-40)$ & $25.2(15-38)^{*}$ \\
Women on HAART prophylaxis (\%) & $44 / 44(100 \%)$ & \\
Gestational age in weeks at the introduction of HAART & $19.5(0-36.3)$ & $28.2(1-39.1)$ \\
Gestational age in weeks at first HIV viral load $<400 \mathrm{copies} / \mathrm{mL}$ & $28 / 44(63.6 \%)$ & $9 / 45(20 \%)^{+}$ \\
Women who reached viral load $<400 \mathrm{copies} / \mathrm{mL}$ during pregnancy $(\%)$ & $10.7(1-35.7)$ & $3 / 45(6.7 \%)^{+}$ \\
Weeks of gestation with viral load $<400 \mathrm{copies} / \mathrm{mL}$ & $25 / 44(56.8 \%)$ & $3358.1(2825-4050)^{\star *}$ \\
Women with HIV viral load $<50 \mathrm{copies} / \mathrm{mL}$ at delivery & $1569.4(55-5660)$ & $39.6(37.0-42.0)^{\star *}$ \\
Viral load in women with $>50 \mathrm{copies} / \mathrm{mL}$ at delivery & $44 / 44(100 \%)$ & $37 / 44(84.1 \%)$ \\
Caesarean section & $2874.8(1795-4065)$ & $37.7(31.1-40.7)$ \\
Elective caesarean section & & \\
Birth weight in g & & \\
Gestational age in weeks & & \\
\hline
\end{tabular}

Data are reported as means with range in parentheses or number with percent in parentheses. ENI = HIV-exposed uninfected neonates (44 mothers and 45 neonates). CT = control healthy neonates (45 mothers and 45 neonates). HAART = highly active antiretroviral therapy.

${ }^{*} \mathrm{P}=0.01$ ( $t$-test), ${ }^{* *} \mathrm{P}<0.001$ ( $t$-test), ${ }^{+} \mathrm{P}<0.001$ (chi-square test) compared to ENI neonates. 
CD34+ progenitors. Progenitor cells were identified as CD45+CD34+ cells.

\section{Measurement of plasma IL-7}

IL-7 was measured in plasma samples from 21 exposed uninfected neonates, 20 control neonates, 19 children from the exposed infant group, and 20 healthy children from the control infant group. The test was performed using a high-sensitivity enzyme-linked immunosorbent assay kit (Quantikine HS human IL-7; R\&D, USA) according to manufacturer instructions. The minimum detectable concentration of IL-7 using this kit is typically $0.1 \mathrm{pg} / \mathrm{mL}$.

\section{Statistical analysis}

Group characteristics at study entry were compared using the $t$-test or chi-square test. For peripheral blood leukocytes and phenotype analyses, the $t$-test was performed. Logarithmic transformation was done when necessary in order to normalize the distribution. Level of significance was set at $P<0.05$.

\section{Results}

Neonate subset

Peripheral blood leukocytes. Exposed uninfected neonates had higher lymphocyte and basophil counts than control neonates but lower hemoglobin concentration, neutrophil and monocyte counts. Mean white blood cells, platelets and eosinophils were similar in the two groups (Table 2).

CD3+, CD4+ and CD8+ total T cells, B cells, NK cells and $C D 45+C D 34+$ progenitors. No differences were observed between the groups when absolute numbers of CD3+, CD4+, and CD8+ T cells, B cells, NK cells and CD45+CD34+ cells were analyzed in neonates (Table 3 ).

CD4+ and CD8+ $T$ cell subsets. Exposed uninfected neonates showed higher mean percentages of central memory CD4+ $T$ (Figure 1A) and central memory CD8+ $T$ cells (Figure $1 B$ ), with lower mean percentages of naive CD4+ $T$ cells (Figure $1 A$ ) and naive CD8+ $T$ cells (Figure 1B).

Table 2. Blood count of HIV-exposed uninfected (ENI) and control healthy (CT) neonates at birth (cord blood) and of infants at 12 months of age.

\begin{tabular}{|c|c|c|c|c|}
\hline \multirow[t]{2}{*}{ Parameters } & \multicolumn{2}{|c|}{ Cord blood } & \multicolumn{2}{|c|}{ Peripheral blood (12 months) } \\
\hline & ENI neonates $(N=45)$ & CT neonates $(\mathrm{N}=45)$ & ENI infants $(\mathrm{N}=23)$ & CT infants $(\mathrm{N}=23)$ \\
\hline White blood cells (cells $/ \mathrm{mm}^{3}$ ) & $12,538(4040-43,060)$ & $13,000(8200-34,000)$ & $12,700(6800-25,400)$ & $10,500(7300-17,100)^{*}$ \\
\hline Hemoglobin (g/dL) & $14.3(10.8-18.5)$ & $15.1(11.2-17.6)^{*}$ & $11.9(10.4-13.1)$ & $11.5(9.5-13.6)$ \\
\hline Platelets $\left(/ \mathrm{mm}^{3}\right)$ & $287,380(57,000-467,000)$ & $303,500(113,000-522,000)$ & $469,000(278,000-694,000)$ & $429,400(305,000-732,000)$ \\
\hline Neutrophils (cells/mm³) & $5182(1620-18,100)$ & $6800(2900-17,300)^{\star *}$ & $4600(1500-8600)$ & $3700(1900-6500)$ \\
\hline Monocytes (cells/mm³) & $830(200-2100)$ & $1000(500-2700)^{*}$ & $900(300-1500)$ & $800(500-1100)$ \\
\hline Eosinophils (cells/mm³) & $4500(30-5990)$ & $5000(40-52,600)$ & $400(10-15,900)$ & $500(100-2700)$ \\
\hline Basophils (cells/mm³) & $274(30-2440)$ & $100(40-200)^{*}$ & $20(0-107)$ & $0(0-0)^{*}$ \\
\hline Lymphocytes (cells/mm³) & $6216(1350-23,250)$ & $4700(1900-12,900)^{*}$ & $6900(3700-16,000)$ & $5500(3400-8900)^{*}$ \\
\hline
\end{tabular}

Data are reported as mean and range.

${ }^{*} \mathrm{P}<0.05$ and ${ }^{* *} \mathrm{P}<0.01$ compared to ENI neonates ( $t$-test).

Table 3. CD3+, CD4+ and CD8+ total T cells, B cells, natural killer (NK) cells and CD45+CD34+ progenitors in HIV-exposed uninfected (ENI) and in control healthy (CT) neonates at birth (cord blood) and in infants at 12 months of age.

\begin{tabular}{|c|c|c|c|c|}
\hline \multirow{2}{*}{$\begin{array}{l}\text { Subset } \\
\left(\text { cells } / \mathrm{mm}^{3}\right)\end{array}$} & \multicolumn{2}{|c|}{ Cord blood } & \multicolumn{2}{|c|}{ Peripheral blood (12 months) } \\
\hline & ENI neonates $(\mathrm{N}=45)$ & CT neonates $(\mathrm{N}=45)$ & ENI infants $(N=23)$ & CT infants $(N=23)$ \\
\hline $\mathrm{CD}^{+} \mathrm{T}$ cells & $2235.7(610.1-7680.7)$ & $1820.3(531.4-5684.8)$ & 3965.5 (1756.3-7707.0) & 3343.5 (1959.4-5320.5) \\
\hline $\mathrm{CD}^{+}{ }^{+} \mathrm{T}$ cells & $1448.6(433.7-3963.4)$ & $1267.1(236.7-2986.2)$ & $2481.0(1102.1-4290.8)$ & 1974.5 (1214.3-3671.1) \\
\hline $\mathrm{CD}^{+} \mathrm{T}$ cells & $645.4(104.9-1823.5)$ & $539.0(188.1-1728.7)$ & $1181.8(405.5-2672.0)$ & 1008.7 (562.6-1734.6) \\
\hline B cells & $690.2(70.4-2404.2)$ & $699.4(31.2-2175.7)$ & $1806.6(736.0-6620.8)$ & 1440.9 (791.4-2581.7) \\
\hline NK cells & $1086.5(101.6-5903.2)$ & 934.7 (268.1-9006.6) & $771.0(110.0-1822.1)$ & $440.8(143.6-1468.5)^{*}$ \\
\hline $\mathrm{CD} 45^{+} \mathrm{CD} 34^{+}$progenitors & $115.9(4.4-389.6)$ & $113.1(292.4-5089.8)$ & $18.8(0.8-50.0)$ & $29.6(4.8-86.8)$ \\
\hline
\end{tabular}

Data are reported as mean and range.

${ }^{*} \mathrm{P}<0.01$ compared to ENI neonates ( $t$-test). 
Expression of activation markers on $C D 4+$ and $C D 8+T$ cells. CD38 expression was statistically higher in the exposed uninfected neonates compared with the controls (Figure 2A).

CD38 expression evaluated as the percentage of CD38positive cells showed similar results for cord CD8+ T cells (ENI, 92.1 vs CT, 88.2\%, P = 0.048, $t$-test) but the difference was not statistically significant for cord CD4+ T cells (ENI, 95.8 vs CT, 93.6\%, $\mathrm{P}=0.129$, $t$-test).

Plasma IL-7 in neonates. Plasma IL-7 concentrations were similar in HIV-exposed neonates and healthy neonates (4.2 vs $4.5 \mathrm{pg} / \mathrm{mL})$.

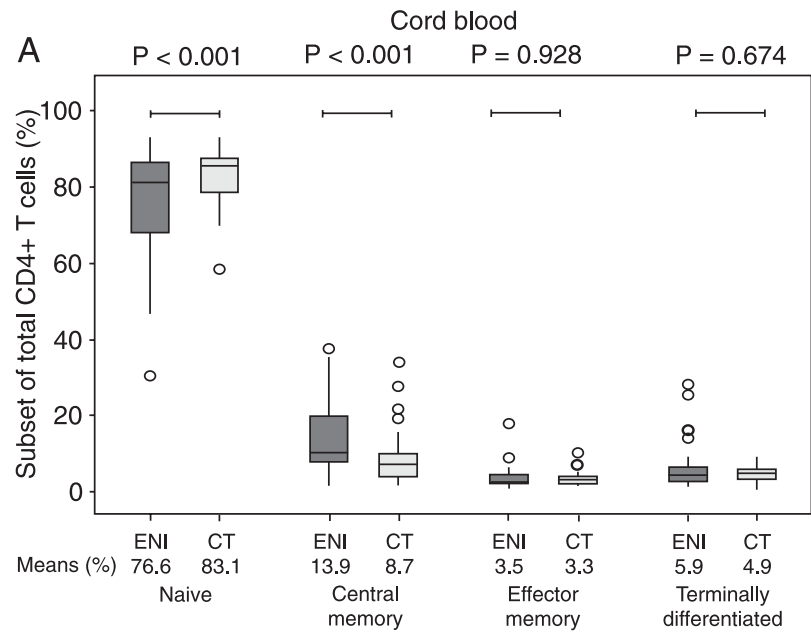

Cord blood

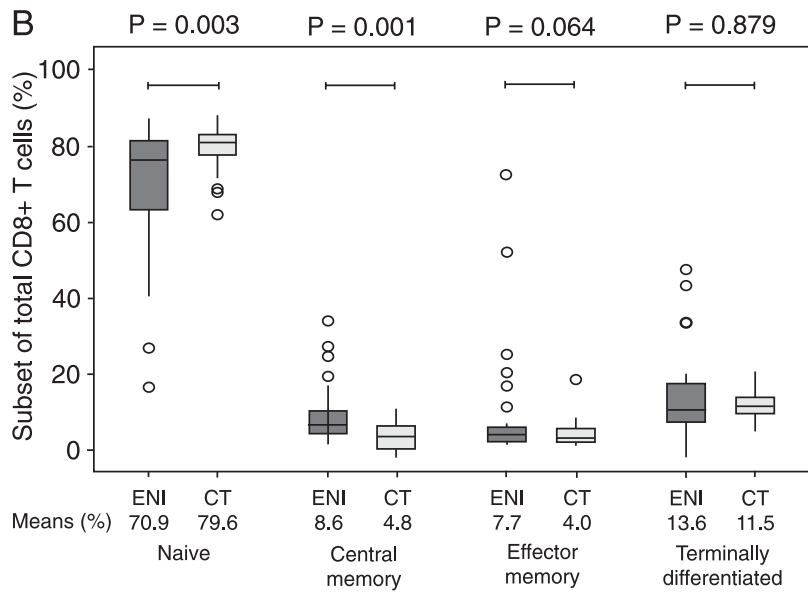

\section{Infant subset}

Peripheral blood leukocytes. Mean white blood cells, lymphocytes and basophils were higher in the HIV-exposed uninfected infants than in the controls. Mean hemoglobin level, number of platelets, neutrophils, monocytes, and eosinophils were not different in the two groups of children (Table 2).

CD3+, CD4+ and CD8+ total T cells, B cells, NK cells and $C D 45+C D 34+$ progenitors. Mean NK cell values were higher in exposed uninfected infants than in controls. No statistical differences were observed between the groups when absolute numbers of CD3+, CD4+, and CD8+ T
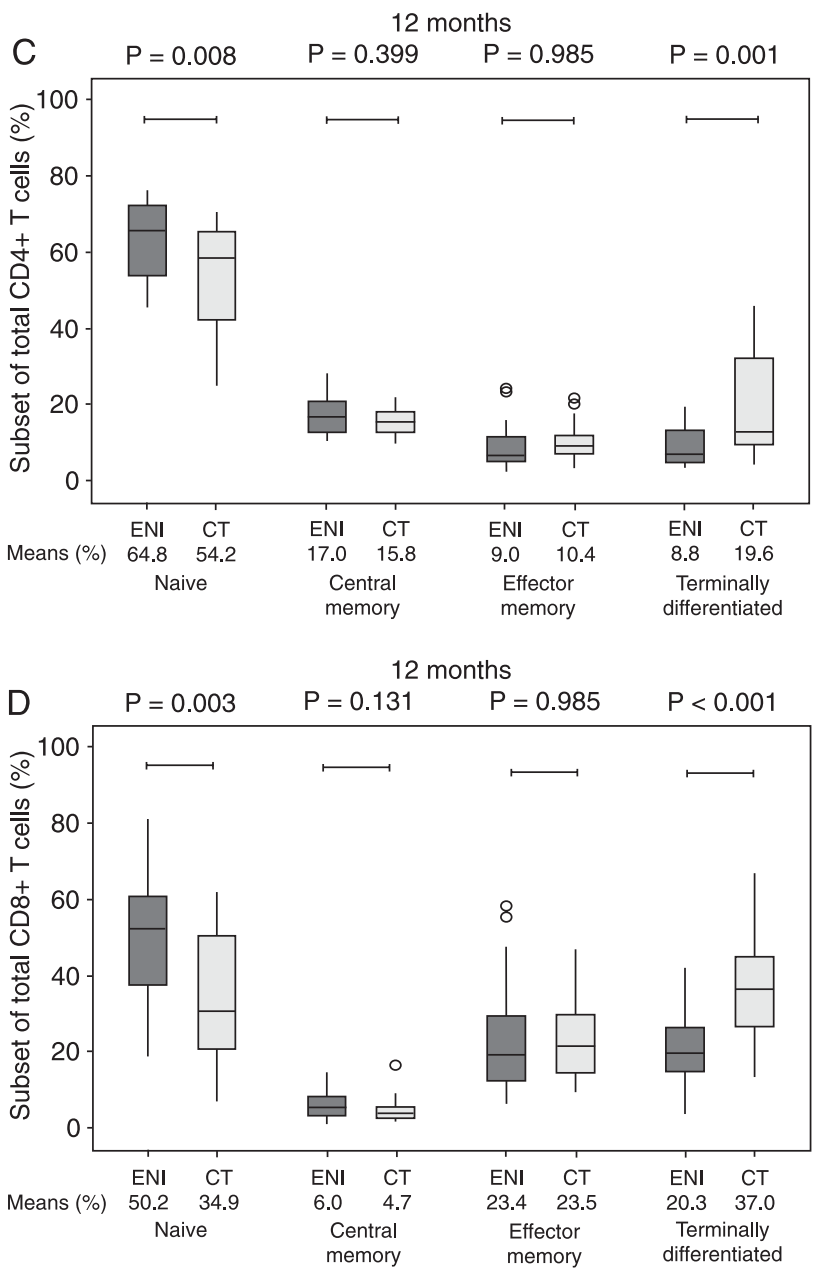

Figure 1. CD4+ and CD8+ T cell subsets using CD45RA and CCR7 markers in HIV-exposed uninfected (ENI) and in control healthy (CT) neonates at birth (cord blood) and in infants at 12 months of age. A, CD4+ T cell subset in 45 HIV-exposed uninfected neonates and in 45 control healthy neonates. $B, C D 8+T$ cell subset in 45 HIV-exposed uninfected neonates and in 45 control healthy neonates. $C$, CD4+ T cell subset at 12 months of age in $23 \mathrm{HIV}$-exposed uninfected infants and in 23 control healthy infants. $D$, CD8+ T cell subset at 12 months of age in $23 \mathrm{HIV}$-exposed uninfected infants and in 23 control healthy infants. Horizontal lines in box plots indicate the 25th, 50th, and 75th percentiles; top and bottom vertical lines mark extreme values and, when present, the small circles represent outlying values. The $t$-test was used for statistical analysis. 
cells, B cells and CD45+CD34+ progenitors were analyzed (Table 3 ). However, mean CD3+ T cells (3965.5 vs 3343.5 cells $/ \mathrm{mm}^{3}, \mathrm{P}=0.080, t$-test) and CD4+ $\mathrm{T}$ cells (2481.0 vs 1974.5 cells $/ \mathrm{mm}^{3}, \mathrm{P}=0.072, t$-test) showed a trend to higher numbers in exposed infants. By contrast, CD45+CD34+ progenitors showed an opposite trend, with higher values in control infants (18.8 vs 29.6 cells $/ \mathrm{mm}^{3}, \mathrm{P}$ $=0.061$, $t$-test $)$.

CD4+ and CD8+ T cell subsets. Exposed uninfected infants showed significantly higher mean percentages of naive CD4+ T cells, with lower mean percentages of terminally differentiated CD4+ T cells (Figure 1C). Mean percentages of naive CD8+ T cells were also higher in the exposed uninfected infants with lower mean percentages of terminally differentiated CD8+ T cells (Figure 1D). The percentages of central and effector memory cells were

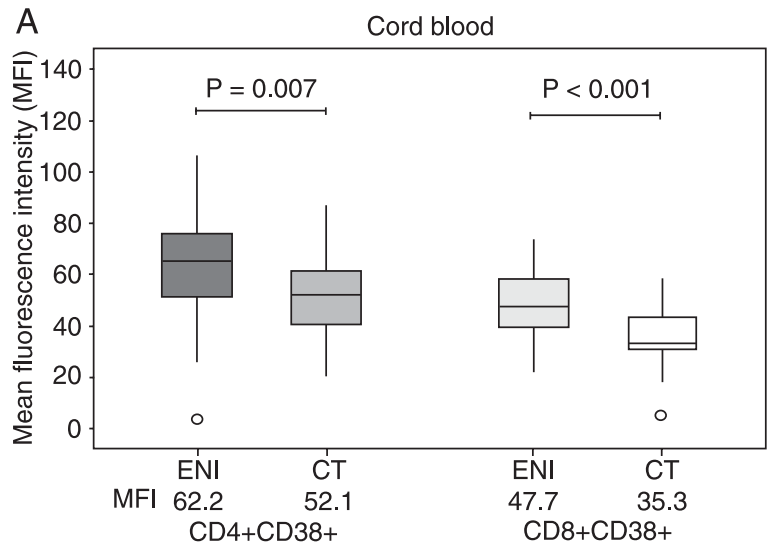

$\mathrm{B}$

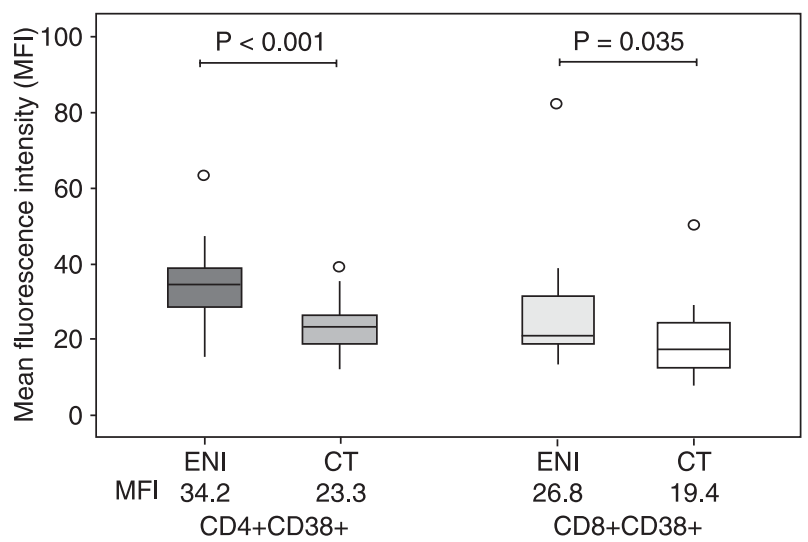

Figure 2. Mean fluorescence intensity of CD38+ in CD4+ and CD8+ T cells in HIV-exposed uninfected (ENI) and in control healthy children (CT) at birth (cord blood) and at 12 months of age. $A, C D 4+$ and CD8+ T cells in HIV-exposed ENI and in CT neonates. $B, C D 4+$ and $C D 8+T$ cells at 12 months of age in HIVexposed ENI and in CT infants. The box plot is described in the legend to Figure 1. The $t$-test was used for statistical analysis. similar between both groups for both CD4+ T cells (Figure $1 C$ ) and CD8+ T cells (Figure 1D).

Expression of activation markers on $\mathrm{CD} 4+$ and $C D 8+T$ cells. CD38 expression was significantly higher on CD4+ T cells from exposed uninfected infants compared to the controls. CD38 expression on CD8+ T cells was also higher in exposed uninfected children than in the controls (Figure 2B).

Similar to that which was observed for cord blood, peripheral CD38+CD4+ T cells (ENI, 83.4 vs $\mathrm{CT}, 74.3 \%, \mathrm{P}$ $=0.004, t$-test) and CD38+CD8+ T cells (ENI, 83.4 vs CT, $63.2 \%, \mathrm{P}=0.010$, $t$-test) were more prevalent in ENI children at 12 months of age when compared to CT infants.

Plasma IL-7 in children at 12 months of age. Plasma IL7 concentrations were significantly lower in the HIV-exposed children at 12 months of age compared to the control infants at 12 months of age $(5.2$ vs $6.8 \mathrm{pg} / \mathrm{mL}, \mathrm{P}=$ 0.012 , $t$-test).

\section{Discussion}

In 2000, Clerici et al. (4) described an increased expression of immune activation markers in $20 \mathrm{HIV}$-exposed uninfected infants compared with 14 healthy HIV-nonexposed infants. They suggested that those findings could be explained by the exposure to HIV in utero.

In the present study, analyzing a population more than twice as large as Clerici's, we looked for similar immune parameter changes in ENI born to HIV-infected mothers treated with state-of-the-art interventions to prevent motherto-child transmission of HIV. Our results demonstrate that, despite adequate prophylaxis, these neonates still presented a different immunologic profile of CD4+ and CD8+ T cells when compared to neonates born to HIV-uninfected mothers, with a shift from naive to memory/effector phenotypes and higher activation by CD38 expression. At 12 months of age, HIV-1-exposed infants maintained an upregulation of $\mathrm{CD} 38$.

In HIV-exposed uninfected neonates, lower birth weight and smaller gestational age could be related to the higher rates of elective cesarean section in this group $(9,10)$. However, anti-retroviral drugs prescribed to the mothers might have also contributed. The same observations have been reported by Briand et al. (11).

HIV-exposed uninfected children had lower hemoglobin levels, less neutrophils and monocytes, and higher basophils and lymphocytes at birth. Lower hemoglobin levels and neutropenia $(12,13)$ have been shown previously in infants exposed in utero to antiretroviral drugs. In a recent publication, different antiretroviral schemes led to diverse toxic effects (14). In our study, hemoglobin levels 
and neutrophils were similar in the groups at 12 months.

Basophils were higher in HIV-exposed neonates, which persisted until 12 months of age in our group. ZaccarelliFilho et al. (15) have also reported high basophil numbers in HIV-infected children. These cells are known to be elevated in conditions associated with Th2 responses (16). In fact, it has been suggested that HIV infection could drive the immune system to a humoral response $(16,17)$. In the same way, HIV-exposed neonates and infants might manifest a Th2 response.

The presence of a low percentage of naive $T$ cells and a high percentage of central memory $T$ cells, with a high CD38 expression, suggests that there may have been exposure of the fetal immune system to HIV antigens in utero. Despite the low or even undetectable viral load levels observed in HIV-1-infected mothers at delivery, these infants may have been previously exposed to the virus during their fetal life, resulting in premature activation and differentiation of $\mathrm{T}$ cells.

In fact, only $63.6 \%$ of HIV-infected women in our study attained and maintained a viral load below 400 copies $/ \mathrm{mL}$ during gestation. Of those who reached low HIV viral load levels, the mean period was for 10.7 weeks, which unquestionably contributed to the lack of in utero HIV infection. However, low viral load levels during the last 10 weeks of pregnancy might have not been enough to avoid antigenic exposure and its immunologic consequences.

Previous studies by our group and others in perinatal HIV-exposed infants have reported evidence of HIV-specific immune response $(4,18-25)$. HIV-specific immune response has also been observed in exposed noninfected adults (26-29).

Interestingly, Schenal et al. (30) showed that whereas HIV-exposed uninfected adults had high central memory HIV-specific cells, HIV-infected patients had higher levels of the HIV-specific effector memory subset. A predominance of central memory over effector memory percentages was observed for total T cells in our study. Schenal et al. concluded that the same immunologic stimuli/signals that lead to prolonged immune activation in HIV-seropositive patients also occurred in exposed uninfected individuals. However, low viral load exposure could lead to higher central memory percentages.

In the present study, despite only being exposed to HIV up to delivery, infants still maintained upregulated immune activation markers at 12 months of age, along with high numbers of NK cells. NK cells are members of the innate immune system and increased interferon- $\gamma$ production by these cells has been found in HIV-exposed uninfected adults (31). On the other hand, low NK cell numbers have been linked to progression to HIV disease $(32,33)$. Therefore, it is possible that NK cells might have had a protective role in avoiding infection in HIV-1-exposed infants.

In contrast to Clerici et al. (4), we did not find high IL-7 plasma levels in HIV-exposed neonates. Moreover, the fact that those children at 12 months of age had a tendency to present higher CD4+ T cells might have contributed to lower IL-7 plasma levels at that age in comparison to nonHIV-exposed controls.

HIV-1-exposed infants still had different immunologic parameters at 12 months of age, although higher naive CD4+ and CD8+ T cells were an unexpected finding. In the same way that HIV-infected children who respond to HAART increase the naive subset of T cells (34-36), it is possible that no further HIV exposure after birth might lead to reduction in the proportion of central memory CD4+ and CD8+ T cells and, as a consequence, an increase in naive T cells in children born to HIV-1-infected mothers.

However, it is not possible to clearly ascertain whether some abnormalities have resulted from the antiretroviral drug exposure during pregnancy. Moreover, another possibility that might be considered is the altered maternal immune environment, which, per se, could have contributed to the findings.

In conclusion, we have shown that HIV-exposed uninfected children present many differences in cellular immune parameters at birth that persist at least for one year. Among those, a state of immune activation is probably the most striking and might have consequences not always immediately identified, but may result in distinct immune responses, including those to vaccine antigens previously reported by our group (37) and by others (6), with a higher humoral immune response to rubella (37) and lower cellular response to BCG (6). Some have even linked the state of immune activation, even more so than the viral load, to the destruction of CD4+ T cells and progression to AIDS in children (38) and adults (39). Further studies must address whether these findings could have an impact on the cellular immune responses to self and foreign antigens and result in clinical consequences to children born to HIV-1infected mothers. 


\section{References}

1. Quinn TC, Overbaugh J. HIVIAIDS in women: an expanding epidemic. Science 2005; 308: 1582-1583.

2. UNAIDS. 2004 Report on the global AIDS epidemic: 4th global report. UNAIDS/04.16E. Joint United Nations Programme on HIV/AIDS, Geneva, Switzerland. http:// www.unaids.org/bangkok2004/report.html

3. European Collaborative Study. Mother-to-child transmission of HIV infection in the era of highly active antiretroviral therapy. Clin Infect Dis 2005; 40: 458-465.

4. Clerici M, Saresella M, Colombo F, Fossati S, Sala N, Bricalli D, et al. T-lymphocyte maturation abnormalities in uninfected newborns and children with vertical exposure to HIV. Blood 2000; 96: 3866-3871.

5. Nielsen SD, Jeppesen DL, Kolte L, Clark DR, Sorensen TU, Dreves AM, et al. Impaired progenitor cell function in HIVnegative infants of HIV-positive mothers results in decreased thymic output and low CD4 counts. Blood 2001; 98: 398-404.

6. Van Rie A, Madhi SA, Heera JR, Meddows-Taylor S, Wendelboe AM, Anthony $F$, et al. Gamma interferon production in response to Mycobacterium bovis BCG and Mycobacterium tuberculosis antigens in infants born to human immunodeficiency virus-infected mothers. Clin Vaccine Immunol 2006; 13: 246-252.

7. Harari A, Rizzardi GP, Ellefsen K, Ciuffreda D, Champagne $\mathrm{P}$, Bart PA, et al. Analysis of HIV-1- and CMV-specific memory CD4 T-cell responses during primary and chronic infection. Blood 2002; 100: 1381-1387.

8. Geginat J, Lanzavecchia A, Sallusto F. Proliferation and differentiation potential of human CD8+ memory T-cell subsets in response to antigen or homeostatic cytokines. Blood 2003; 101: 4260-4266.

9. Joseph KS, Kramer MS, Marcoux S, Ohlsson A, Wen SW, Allen A, et al. Determinants of preterm birth rates in Canada from 1981 through 1983 and from 1992 through 1994. N Engl J Med 1998; 339: 1434-1439.

10. Silva AA, Lamy-Filho F, Alves MT, Coimbra LC, Bettiol H, Barbieri MA. Risk factors for low birthweight in north-east Brazil: the role of caesarean section. Paediatr Perinat Epidemiol 2001; 15: 257-264.

11. Briand $N$, Le Coeur $S$, Traisathit $P$, Karnchanamayul V, Hansudewechakul R, Ngampiyasakul C, et al. Growth of human immunodeficiency virus-uninfected children exposed to perinatal zidovudine for the prevention of mother-to-child human immunodeficiency virus transmission. Pediatr Infect Dis J 2006; 25: 325-332.

12. European Collaborative Study. Levels and patterns of neutrophil cell counts over the first 8 years of life in children of HIV-1-infected mothers. AIDS 2004; 18: 2009-2017.

13. Bunders MJ, Bekker V, Scherpbier HJ, Boer K, Godfried M, Kuijpers TW. Haematological parameters of HIV-1-uninfected infants born to HIV-1-infected mothers. Acta Paediatr 2005; 94: 1571-1577.

14. Pacheco SE, Mclntosh K, Lu M, Mofenson LM, Diaz C, Foca $\mathrm{M}$, et al. Effect of perinatal antiretroviral drug exposure on hematologic values in HIV-uninfected children: An analysis of the women and infants transmission study. J Infect Dis 2006; 194: 1089-1097.

15. Zaccarelli-Filho CA, Ono E, Machado DM, Brunialti M, Succi
RC, Salomao R, et al. HIV-1-infected children on HAART: immunologic features of three different levels of viral suppression. Cytometry B Clin Cytom 2007; 72: 14-21.

16. Abbas AK, Lichtman AH. Effector mechanisms of cell-mediated immunity. In: Abbas AK, Lichtman AH, Pober JS (Editors), Cellular and molecular immunology. Philadelphia: Elsevier; 2008. p 298-317.

17. Clerici M, Shearer GM. The Th1-Th2 hypothesis of HIV infection: new insights. Immunol Today 1994; 15: 575-581.

18. Aldhous MC, Watret KC, Mok JY, Bird AG, Froebel KS. Cytotoxic $T$ lymphocyte activity and CD8 subpopulations in children at risk of HIV infection. Clin Exp Immunol 1994; 97: 61-67.

19. De Maria A, Cirillo C, Moretta L. Occurrence of human immunodeficiency virus type 1 (HIV-1)-specific cytolytic T cell activity in apparently uninfected children born to HIV-1infected mothers. J Infect Dis 1994; 170: 1296-1299.

20. McFarland EJ, Harding PA, Luckey D, Conway B, Young RK, Kuritzkes DR. High frequency of Gag- and envelopespecific cytotoxic $T$ lymphocyte precursors in children with vertically acquired human immunodeficiency virus type 1 infection. J Infect Dis 1994; 170: 766-774.

21. Luzuriaga K, Holmes D, Hereema A, Wong J, Panicali DL, Sullivan JL. HIV-1-specific cytotoxic T lymphocyte responses in the first year of life. J Immunol 1995; 154: 433443.

22. Levy JA, Hsueh F, Blackbourn DJ, Wara D, Weintrub PS. CD8 cell noncytotoxic antiviral activity in human immunodeficiency virus-infected and -uninfected children. $J$ Infect Dis 1998; 177: 470-472.

23. Wasik TJ, Bratosiewicz J, Wierzbicki A, Whiteman VE, Rutstein RR, Starr SE, et al. Protective role of beta-chemokines associated with HIV-specific Th responses against perinatal HIV transmission. J Immunol 1999; 162: 43554364.

24. Kuhn L, Coutsoudis A, Moodley D, Trabattoni D, Mngqundaniso N, Shearer GM, et al. T-helper cell responses to HIV envelope peptides in cord blood: protection against intrapartum and breast-feeding transmission. AIDS 2001; 15: 1-9.

25. Legrand FA, Nixon DF, Loo CP, Ono E, Chapman JM, Miyamoto M, et al. Strong HIV-1-specific T cell responses in HIV-1-exposed uninfected infants and neonates revealed after regulatory T cell removal. PLOS ONE 2006; 1: e102.

26. Clerici M, Giorgi JV, Chou CC, Gudeman VK, Zack JA, Gupta $\mathrm{P}$, et al. Cell-mediated immune response to human immunodeficiency virus (HIV) type 1 in seronegative homosexual men with recent sexual exposure to HIV-1. J Infect Dis 1992; 165: 1012-1019.

27. Clerici M, Levin JM, Kessler HA, Harris A, Berzofsky JA, Landay $\mathrm{AL}$, et al. HIV-specific T-helper activity in seronegative health care workers exposed to contaminated blood. JAMA 1994; 271: 42-46.

28. Fowke KR, Kaul R, Rosenthal KL, Oyugi J, Kimani J, Rutherford WJ, et al. HIV-1-specific cellular immune responses among HIV-1-resistant sex workers. Immunol Cell Biol 2000; 78: 586-595.

29. Alimonti JB, Koesters SA, Kimani J, Matu L, Wachihi C, Plummer FA, et al. CD4+ T cell responses in HIV-exposed seronegative women are qualitatively distinct from those in 
HIV-infected women. J Infect Dis 2005; 191: 20-24.

30. Schenal M, Lo CS, Fasano F, Vichi F, Saresella M, Pierotti $\mathrm{P}$, et al. Distinct patterns of HIV-specific memory T lymphocytes in HIV-exposed uninfected individuals and in HIVinfected patients. AIDS 2005; 19: 653-661.

31. Montoya CJ, Velilla PA, Chougnet C, Landay AL, Rugeles MT. Increased IFN-gamma production by $\mathrm{NK}$ and $\mathrm{CD} 3+$ / CD56+ cells in sexually HIV-1-exposed but uninfected individuals. Clin Immunol 2006; 120: 138-146.

32. Ullum H, Gotzsche PC, Victor J, Dickmeiss E, Skinhoj P, Pedersen BK. Defective natural immunity: an early manifestation of human immunodeficiency virus infection. J Exp Med 1995; 182: 789-799.

33. Alter G, Malenfant JM, Delabre RM, Burgett NC, Yu XG, Lichterfeld $\mathrm{M}$, et al. Increased natural killer cell activity in viremic HIV-1 infection. J Immunol 2004; 173: 5305-5311.

34. Resino S, Galan I, Perez A, Leon JA, Seoane E, Gurbindo $D$, et al. HIV-infected children with moderate/severe immune-suppression: changes in the immune system after highly active antiretroviral therapy. Clin Exp Immunol 2004; 137: 570-577.

35. Gonzalez I, Gil L, Molina R, Gonzalez A, Toledo ME, Diaz-
Jidy M, et al. Immunological characteristic of children vertically infected with HIV: a case-control study. Rev Invest Clin 2005; 57: 498-504.

36. Lambert JS, Moye J Jr, Plaeger SF, Stiehm ER, Bethel J, Mofenson LM, et al. Association of selected phenotypic markers of lymphocyte activation and differentiation with perinatal human immunodeficiency virus transmission and infant infection. Clin Diagn Lab Immunol 2005; 12: 622-631.

37. Lima M, De Menezes Succi RC, Nunes Dos Santos AM, Weckx LY, de Moraes-Pinto MI. Rubella immunization in human immunodeficiency virus type 1-infected children: cause for concern in vaccination strategies. Pediatr Infect Dis J 2004; 23: 604-607.

38. Resino S, Seoane E, Gutierrez MD, Leon JA, MunozFernandez MA. CD4(+) T-cell immunodeficiency is more dependent on immune activation than viral load in HIVinfected children on highly active antiretroviral therapy. $J$ Acquir Immune Defic Syndr 2006; 42: 269-276.

39. Rodriguez B, Sethi AK, Cheruvu VK, Mackay W, Bosch RJ, Kitahata M, et al. Predictive value of plasma HIV RNA level on rate of CD4 T-cell decline in untreated HIV infection. JAMA 2006; 296: 1498-1506. 